\title{
La Argumentación Jurídica y su utilidad frente a la Práctica del Derecho
}

The Legal Argumentation and its utility against the Practice of Law

\section{María Isabel Zamora Zumárraga}

Investigadora Jurídica, Cevallos \& Noboa

Artículo Original (Revisión)

RFJ, No. 2, 2017, pp. 147-168, ISSN 2588-0837

RESUMEN: la práctica del Derecho consiste esencialmente en la argumentación, por ello es importante anunciar como sus operadores se desenvuelven en elámbito de la lógica argumentativa, con la cual, por medio de la razón y en conjunto con otras ciencias, que complementan este ejercicio tan trascendental, mejorarán su desempeño como legisladores, jueces y abogados. ¿Es la educación, desde el pregrado, el punto inicial para aprender argumentación jurídica? De serlo, será posible esbozar soluciones práctico-teóricas a las falencias educativas, encaminar la educación legal hacia la consecución del éxito de los futuros abogados del Ecuador y a la real y justa aplicación de la normativa jurídica.

PALABRAS CLAVE: argumentación jurídica, lógica jurídica, interdisciplinariedad del Derecho, función del Derecho, funcionarios del Derecho.

ABSTRACT: the practice of law consists basically in argumentation, that is why it is important to say how their functionaries get on with logic argumentation, through reason and other sciences which complete these fundamental exercise, they get better their performance as legislator, judge and lawyer.

Is education from undergraduate, the starting point to learn legal argumentation? If it is true, it will be possible to sketch practical and theoretical solutions for every lack in education, directing legal instruction to get successful Ecuadorian lawyers and the fair and real application of legal rules. 
KEY WORDS: legal argumentation, legal logic, interdisciplinarity of law, function of law, law officials.

\section{INTRODUCCIÓN}

Al establecer los desperfectos de la educación inicial del Derecho, mencionaralgunos conceptos y su relación directa con laargumentación jurídica, resulta un buen inicio para llegar a la proposición de opciones para llenar cada vacío y falencia de manera rectificadora.

Las funciones originales de estos conceptos y mecanismos se ven oscurecidos en la adquisición teórica y su práctica debido al paso del tiempo, los intereses personales y la desidia. Por ello es necesario sugerir soluciones útiles, con el objetivo de ampliar la visión y motivar a los dos actores principales de este intercambio de conocimiento: alumno y maestro.

El abogado desde su educación inicial deberá acumular destrezas jurídicas entre sus conocimientos y aptitudes, ellas serán sus herramientas básicas de desempeño. Otro punto importante es mostrar la relación entre el Derecho, la lógica y otras ciencias complementarias, pues aportará al análisis casuístico que deben realizar los operarios jurídicos (abogados, jueces, asesores, etc.) esto resulta propicio para la argumentación lógica en defensa, ya sea oral o escrita de clientes de los futuros abogados.

La lógica debe amparar todo el proceso de preparación y ejecución de las profesiones relacionadas con la ciencia jurídica para combatir los problemas propios del Derecho como el metalenguaje ${ }^{69}$, la autopoiesis y la aplicación rígida de las normas jurídicas. Para ello es vital recordar que el Derecho responde a los problemas sociales, ambos se regulan entre sí.

En un intento de sistematizar rígidamente esta ciencia social se positivizó de tal manera que la norma entró en conflicto con su aplicación real y limitó su campo mitigador de conflictos en las relaciones humanas. Uno de los problemas principales es no diferenciar el conocimiento científico del práctico y a partir de ello no establecer el método óptimo para conseguir la respuesta anhelada. El método

69 Las teorías interpretativas parten que el Derecho es un fenómeno lingüístico (Huerta Ochoa, 2015). 
empírico es complicado en su recolección, el método científico no se puede aplicar en toda actividad o proceso jurídico sino solo en ciertas partes estáticas, las cuales se encuentran en menor número pues el Derecho cambia constantemente, tal como la sociedad de donde deviene su funcionalidad.

Indicar nuevos métodos de razonamiento permitirá una armonía entre las normas y la aplicación de las mismas, al hacer referencia a todo el proceso judicial. La realidad social está fuera de ese aparato racional. En principio, las normas son las que prefiguran la realidad deseable, y es esta última la que debe ajustarse a ellas. Además, las propias normas prevén las consecuencias que han de producirse cuando la realidad discrepe del mandato en ellas contenido ${ }^{70}$. Para ello es necesario explicar la relación entre Derecho y Economía, reconocer la evolución metodológica en la decisión judicial con todas sus etapas.

Identificar nuevas propuestas que acatan una visión interdisciplinaria de las ciencias como: la Economía, la sociología y el Derecho. El ejercicio intelectual, el uso del método apriorístico deductivo, la comprensión de las instituciones jurídicas permite llegar a conclusiones lógicas y beneficiosas. Es importante seguir la pista del Derecho en la realidad para saber si cumple sus fines y esto solo será posible al dejar el estatismo y la necedad jurídica.

Las escuelas positivistas y naturalistas han respondido en dos enfoques respectivamente: aquel en el cual se separa la emotividad y preferencia de la decisión final del juzgador y su contraparte que reconcoce su complementariedad e imposibilidad de esta segmentación. Por ello resulta trascendente exponer algunos incovenientes presentados a lo largo de la actividad judicial como: identificar los principales problemas en relacion con la racionalidad, en un ambito psicologico, y la decisión del juez, explicar los criterios principales que el enjuiciador tendrá que tomar en cuenta y resumir la manera en que se limita el poder judicial en el sistema anglosajón y continental, solo entonces subsanar los errores respecto a esta actividad resulta posible. La pregunta que surge respecto al poder judicial ¿Qué motiva a los jueces a fallar cuando las situaciones A y B tienen una argumentación logicamente correcta? A lo cual ambas escuelas pretenden responder e incluso las ciencias complementarias al Derecho como la Psicología y la Economia con su respectivo analisis de las normas e instituciones de la ciencia jurídica cuando incluso

$70 \quad$ Magaloni Kerpel, 2016. 2. 
es definida como la ciencia de motivación de conductas ${ }^{71}$ pues todos quienes están inmiscuidos en actividades jurídicas se motivan entre sí. Los ciudadanos a los legisladores, ellos marcan un marco de legitimidad para los jueces en el sistema continental o en el caso anglosajón la jurisprudencia, los abogados apelan ante el juez en favor de los intereses de sus clientes e incluso los jueces influyen respecto al actuar de los miembros del poder ejecutivo.

El juez al tener obligación proveniente de dos vertientes: la individual, frente al ciudadano, al justiciable que toca las puertas de un despacho judicial en la desesperada búsqueda de su justicia que la reparación de su Derecho reclama. Y la colectiva, frente a la presencia grupal, sólida y unitaria ante el aparato del Estado al reclamar el sitio y el privilegio que le corresponden como depositario de la voluntad popular en la tarea de la administración judicial ${ }^{72}$, estas vertientes obligan al juez por vías subjetivas y objetivas, en un ámbito ideal a donde tiende el Derecho, a elegir en función del bienestar general y a motivar sus decisiones para lo cual se hace indispensable la argumentación jurídica, tanto como para la legislación y el ejercicio de esta noble profesión.

\section{LÓGICA Y ARGUMENTACIÓN INTERDISCIPLINARIA}

Antes de mostrar la relación entre el Derecho, la lógica y otras ciencias complementarias es importante precisar que la argumentación jurídica permite llegar a conclusiones por medio de afirmaciones lógicas que están fundamentadas en razones aceptadas desde el punto de vista jurisprudencial o del campo de aplicación de los textos normativos. Estas afirmaciones son regularmente utilizadas por las personas que tienen la misión de impartir justicia en el momento de tomar decisiones jurídicas sobre hechos concretos o controversiales.

Las afirmaciones vertidas por los jueces o juristas regularmente descansan en la jurisprudencia, las disciplinas sociales, las ciencias exactas o cualquier otra fuente de argumentación que sea susceptible de aportar elementos para la resolución de hechos o controversias vertidas en el ámbito de la aplicación de la ley ${ }^{73}$. La función de la argumentación en el discurso jurídico es relevante tanto en la investigación

71 Lionetti de Zorzi. 3.

72 Baca d'la Zota, 1989. 5.

73 Suárez Romero y Conde Gaxiola, 2009. 13. 
como en la toma de decisiones, por su carácter de fundamentación del significado atribuido a los enunciados normativos y las consecuencias jurídicas que de ello pueden derivarse ${ }^{74}$.

Es importante también distinguir entre los diversos contextos: uno es el de descubrimiento y otro el de justificación, pues requieren de análisis argumentativos distintos. La psicología social se ha encargado de estudiar el proceso de tomar decisiones por medio de argumentos y así reducir el peso que los prejuicios adquieren en las resoluciones, punto que será tratado más adelante. Para ello se hará uso de la lógica tanto formal como material. Actualmente el mismo Derecho obliga a los jueces y tribunales a motivar correctamente sus decisiones, esto significa algo más que efectuar una operación deductiva consistente en extraer una conclusión a partir de premisas normativas y fácticas ${ }^{75}$. Muchos doctrinarios y teorías sostienen que el funcionario judicial primero se deja llevar por su irracionalidad y luego busca fundamentarla de una manera lógica a lo que Atienza repone así: Es imposible que, de hecho, las decisiones se tomen, al menos en parte, como ellos sugieren, es decir, que el proceso mental del juez vaya de la conclusión a las premisas e incluso que la decisión sea, sobre todo, fruto de prejuicios; pero ello no anula la necesidad de justificar la decisión, ni convierte tampoco esta tarea en algo imposible ${ }^{76}$.

La lógica, por su parte, es una disciplina formal que estudia los razonamientos con fundamento en sus elementos base, por ello el razonamiento jurídico como proceso lógico estaba contemplado como un paso en todo el proceso de aplicación y creación de la normativa jurídica. La lógica es más que un paso dentro del Derecho.

La lógica se relaciona con el Derecho en la medida en que sus operarios deben deducir y pensar para hacer un intento por llegar a una justa sentencia, esto se ve obstaculizado por los problemas antes planteados con el metalenguaje, la mala argumentación sin sustento jurídico- normativo ni jurisprudencia y la autopoiesis. Además de ello se suma la falta de entusiasmo de jueces y abogados para realizar procesos de inferencia, pues esto dificulta su hacer, al preferir utilizar de manera mecánica los conceptos.

74 Huerta Ochoa, 2015. 3.

75 Atienza. (2005). Las Razones del Derecho: Teorías de la argumentación jurídica, 23.

76 Atienza. (2005). Las Razones del Derecho: Teorías de la argumentación jurídica. 
Elementos como la lógica, la inferencia de conceptos y la deducción lógica de sentencias justas y humanas (todo resultado de la investigación previa) conforman la tarea del Derecho, aún con todos estos elementos se encuentran presentes las contradicciones y erratas, esto se debe a que el razonamiento jurídico está hecho por humanos. Frente a esa posibilidad de errores argumentativos y lógicos tan solo queda que tantos jueces, abogados y científicos del Derecho opten por buscar alternativas que se adapten a la realidad y sirvan al propósito de solucionar conflictos, en lugar de generarlos.

Reconocer la evolución metodológica en la decisión judicial destaca todas las fases que esta compleja actividad jurídica posee. Cada fase de este proceso cuenta unos diferentes objetivos que se alcanzan realmente cuando se utiliza un razonamiento propio de dicha fase. Al diferenciar el tipo de actividad, conocimiento y preguntarse qué es lo que se desea alcanzar es momento de vincular no uno, sino varios métodos que se ayudan de manera simbiótica a la decisión judicial.

La utilidad del método deductivo es la contrastación, el avance de la ciencia, el desarrollo de la estadística y principios que se aplicarán casos particulares. La conclusión deductiva solo resuelve como verdadero o falso cuando la naturaleza de las leyes puede ir más allá como si son vigentes, derogadas, justas, injusta, validas o inválidas. Otro de los problemas del método es que busca explicaciones a las predicciones que no son certeras y no es posible tomar riesgos como estos en todas las fases.

El modelo tradicional limita al juez, en palabras de Montesquieu, a ser la boca que pronuncia las palabras de la ley. Esto no es posible porque las sentencias son una expresión de un poder del Estado que debe estar impregnados de razón e inteligencia.

Son inseparables los elementos cognitivos y volitivos de la actividad judicial, pero tampoco puede rayar en la arbitrariedad. Entonces la obligatoriedad de la motivación limita y regula estas dos consideraciones. En conclusión, se debe realizar un análisis interno de la coherencia lógica de la sentencia tal como su justificación valorativa externa. Pero no los motivos psicológicos que tuvo el juez.

Por ejemplo, en el Derecho Penal se tiene que llegar a una decisión por pruebas directas e indirectas. Incluso por indicios conectados por nexos causales y lógicos. Las pruebas de carácter penal usan los 
métodos deductivos e inductivos respecto a la prueba indiciaria justificándose en reglas empíricas. Y el razonamiento deductivo puro al invocar una norma, aplicar a un hecho probado y sentenciar. El conglomerado de razonamientos y fases son lo que le dan suficientes motivos al juez para fallar a favor de una u otra parte porque lo que deben usarse de manera conjugada.

Identificar nuevas propuestas que acatan una visión interdisciplinaria de las ciencias como: la Economía, la sociología y el Derecho muestren un nuevo y dinámico camino del Derecho es el motivo de este documento. Ya se mencionó que no se han reconocido a cabalidad los distintos tipos de conocimientos como son: el conocimiento científico, cuyas características son la racionalidad, organizado y disponible. Y el conocimiento práctico, este se encuentra disperso en las mentes humanas, mantiene una aplicación inconsciente que pertenece a cada uno de los individuos y es allí donde radica el problema con este tipo de conocimiento, pues no puede ser recolectado, incluso su transmisión se imposibilita. Sobre este conocimiento no se puede crear una teoría, ni demostrar una ya existente.

La primera propuesta es el método fraseológico, inspirado en la escuela austriaca de Economía. El Análisis Económico del Derecho es una escuela del Derecho que intenta explicar las conductas jurídicas a partir de la metodología y los conceptos de la ciencia económica, principalmente a partir de la macroeconomía, su objeto de estudio no es el Derecho como un conjunto de normas, sino las conductas humanas relacionadas con el Derecho. Al ser este un sistema coherente que busca la maximización de la riqueza social las decisiones públicas tomadas por el gobierno, así como los individuos y las empresas buscarán la maximización de sus beneficios ${ }^{77}$.

$\mathrm{Al}$ analizarlo cronológicamente al inicio se encontraban estrechamente ligados hasta la formalización de la Economía y la inseparabilidad del Derecho y la moral, aquí es donde se dividen estas ciencias. Hasta que el pensamiento económico neoclasicista encuentra especial interés por la influencia de las instituciones jurídicas en la Economía.

El Derecho y la Economía han Estado vinculados desde hace mucho tiempo.

77 Serrano Migallón, 2015. 17. 
Explicar la relación entre Derecho y Economía tiene sentido al ser ciencias con base teórica común, ambas usan la introspección que por medio del razonamiento lógico permite llegar a conclusiones lógicas, además en su interacción el Derecho afecta y regula el marco en donde se desenvuelve la Economía. Se diferencian en que el Derecho soluciona conflictos de intereses en las relaciones humanas, mientras la Economía estudia estas relaciones conjugándola con la escasez.

Cuando la Economía usa la introspección, método de Menger y Mises, puede compartir su método con el Derecho, más cuando usa fórmulas abstractas y "hechos empíricos". Históricamente, han sido dos las vías por las cuales los economistas se han interesado por el Derecho. Una, el Derecho como un mecanismo de transmisión y reglamentación de aquellas decisiones del soberano que afectan los asuntos económicos. La segunda vía, la del Derecho y de manera más general las instituciones como factor determinante del desempeño económico de las sociedades, se puede enmarcar dentro de las preocupaciones de los pensadores clásicos, que fueron retomadas por la Economía institucional y, más recientemente, por la teoría del desarrollo económico ${ }^{78}$.

"El análisis económico del Derecho permite comprender de mejor forma porque tiene éxito o porque fracasa determinada regulación en su aplicación práctica y cómo lograr llevarla a cabo de forma eficiente."79 Determinar la eficacia en concordancia con la maxificación de beneficios e incentivos externos en forma de norma que modelen el comportamiento humano es un gran aporte que solo se obtiene al adoptar las herramientas que la usa la Economía y adaptarlas al Derecho.

Relacionado con la sustancia de los valores que subyacen al discurso del Análisis Económico del Derecho y la heterogeneidad de estos valores es el asunto de la causa de esta heterogeneidad la pregunta de si este conflicto puede ser una consecuencia de las naturalezas particulares de las categorías de Economía y de Derecho, o la naturaleza inevitable de un discurso que ocurre a través del límite entre las distintas áreas del esfuerzo intelectual o, quizás, la manera particular en la cual ha procedido este discurso ${ }^{80}$. Este método parte del supuesto que el ser humano es individualista y busca un beneficio, en este caso la convivencia, que

\footnotetext{
78 Posner, 2002. 5.

79 Fraga Lo Curto. 7.

80 Brion, 2009. 10.
} 
mediante normas que procedan al empleo del método ensayo-error lleguen a cumplir su función, aúnque los valores implícitos se critiquen.

Las normas jurídicas crean precios implícitos para tipos diferentes de conducta, y las respuestas a esos precios implícitos pueden examinarse de la misma manera en que los economistas examinan la respuesta de los consumidores a los precios explícitos de cualquier bien o servicio ${ }^{81}$. Este método se ocupa en medir la eficiencia mediante dos técnicas: la creatividad empresarial es el uso a beneficio del modo de adaptación y aprendizaje, se usará el proceso ensayo-error, así mismo busca que el Derecho sea creativo en la búsqueda de soluciones a conflictos y diferencias, emplea el mecanismo adaptativo del ser humano en conjunto con la institución jurídica correcta, aquella que solucione mejor el problema. Busca la evolución del ordenamiento jurídico. Además, usa la coordinación de desajustes sociales en favor del uso, creación y transmisión de la información en función de dirigir y administrar ya sea una empresa o un poder estatal ajusta tanto excesos como necesidades. De esta forma tanto los operadores como los destinatarios ganan estabilidad y armonía social en igualdad. Hace útiles las instituciones jurídicas en relación a que tanto beneficia a sus usuarios.

La Segunda Propuesta es el uso de varios métodos según la fase de la actividad judicial en la que se encuentre el juez. Lo cual se halla explicado en la segunda parte de este documento. Al realizar un análisis de a dónde quiere llegar determinada fase de la actividad judicial es posible emplear un método que permita al operador jurídico conseguir su objetivo de manera eficaz para su pronta ejecución, lo que pondrá fin a un conflicto entre actores sociales.

Es importante conocer e integrar las herramientas que otras ciencias cercanas al Derecho pueden proveer. Las ciencias sociales, entre ellas el Derecho deben evolucionar tan rápido como lo hace la humanidad pues en ella se encuentra su materia de estudio y aplicación. Es tan complejo normar una sociedad de manera eficiente que la absolutización del método deductivo se queda corta. Si el fin del Derecho es la solución de conflictos tiene que adoptar nuevas maneras para proporcionar soluciones efectivas.

81 Mendez Reátegui, 2008. 58. 


\section{REVISIÓN DE FUNCIONES Y FUNCIONARIOS DEL DERECHO}

El buen jurista debe poseer la capacidad de idear y manejar argumentos $^{82}$ con facilidad y habilidad aúnque no se hayan especializado teóricamente en el proceso de la correcta argumentación, sino sea producto de la práctica y el ejercicio de su profesión. El abogado tiene y presume de destrezas específicas que son como las manos del artesano, su manera de cumplir su función, sin un repertorio de estas habilidades ¿cómo ha de defender a quienes no las poseen?

La comunicación verbal y no verbal son destrezas vitales para el operario jurídico, pues la argumentación se puede dominar a partir de estudiar el lenguaje, en el acto de hablar con otros se podrá construir la verdad que posteriormente será aceptada o no. El éxito de los argumentos está relacionado en función de la relación o correspondencia entre lo que se afirma y los hechos, es decir entre el lenguaje y las cosas concretas e históricas.

"El abogado, como el actor, es un palabreador. Importan, pues, el timbre y los tonos de su voz, su sonoridad, las inflexiones o matices, el aliento y hasta los tempos musicales. Ambos usan recursos y efectos para convencer. Linda palabra. Con-vencer. Vencer ambos. O ser ambos vencidos por la razón." ${ }_{3}$

Es mediante la comunicación verbal y gestual como consigue clientes, los convence de su aptitud, explica la problemática al juez, intenta ganar, entre otras necesidades. La exageración como la inexistencia de expresiones derivaría en un grave problema de ineptitud del letrado, para quien si aún con todo el conocimiento no puede sacar provecho de él. Soltura, pero moderación como dice Hamlet en esto tu propia discreción ha de guiarte.

82 Un argumento es una afirmación provista de razonamiento que busca probar algo. $\mathrm{Al}$ argumentar se busca exponer las razones que justifican una idea, hecho, conducta, interpretación o significado; con la intención que sea creíble o aceptada. En este sentido la argumentación será puesta a prueba en todo momento, sin embargo, la argumentación no implica mostrar las pruebas irrefutables de la afirmación vertida, por el contrario se busca sóoo convencer o persuadir al receptor del mensaje Suárez Romero y Conde Gaxiola, 2009

Blume, 1990. 
La lectura lógica-reflexiva no puede esta fuera de aquel catálogo de destrezas jurídicas, muchos estudiantes de Derecho desarrollan tedio a la lectura, cuando es la lectura la que fomenta el análisis y la reflexión. El problema radicaría en cómo se maneja el tema de la lectura desde las facultades de Jurisprudencia, los controles de lectura no representan el conocimiento del alumno y lo mortifican.

Leer adecuadamente (modo analítico) conforma una parte indispensable para el abogado, quien, si no se empapa del caso mediante la lectura, no podrá comprender completamente el conflicto. Mucho menos aconsejar y defender un propósito. La lectura es la herramienta más importante para el desempeño del operario jurídico, es esta la que le provee de argumentos para toda forma de aplicación de la norma.

La redacción apropiada es la marca personal del operario del Derecho. Un juez o abogado que presente un dictamen o replica con incongruencias, o peor aún faltas de ortografía, pondrá en tela de duda todo el resto de su catálogo de destrezas. Existen varios casos que se han librado con una clara declaración de los hechos redactada por el defensor de parte. La escritura aún en un sistema oral como el COGEP no dejará de ser gravitante.

Finalmente, las técnicas de investigación y análisis de la información son un plus facilitador para el abogado, conocerlas le permitirá ahorrar tiempo y esfuerzo, además de contar con resultados veraces y apegados a los ideales de justicia. Esta destreza es esencial para el abogado y su representado pues los favorece o perjudica al no poseerlas.

Esta argumentación tiene tres fases como son: la legislativa, aplicación judicial y el dogmático. Una de las diferencias radica en como la aplicación judicial se dedica a resolver casuísticamente circunstancias donde chocan intereses de dos o más miembros de la sociedad a la que pertenecen, mientras la fase dogmática se ocupa de situaciones abstractas, mejor orientadas a ayudar a sus congéneres. Aún con esta diferenciación ambas fases de ayudan simultánea y simbióticamente. Un ejemplo de ello es cuando al crear jurisprudencia la ratio decidendi combina un caso concreto con los ideales abstractos del Derecho para crear precedentes y que estos se respeten en casos futuros.

Explicar los criterios principales que el enjuiciador tendrá que tomar en cuenta es el paso inicial para entender esta actividad base de la armonia social. La teoria de la elección social toma en cuenta cuatro 
criterios como: coherencia, individualismo, consecuencialismo e individualismo. Mientras el análisis económico del Derecho se basa en la eficiencia y la maxificación de beneficios al menor costo posible, incluye de mejor manera la racionalidad para poder analizar los fallos.

Para exponer algunos inconvenientes presentados a lo largo de la actividad judicial es preciso identificar los principales problemas en relación con la racionalidad, en un ámbito psicológico, y la decisión del juez permite analizar que mueve las decisiones cuando la razón no es suficiente, debido a un relación directamente proporcional entre los defectuosos métodos usados y el nivel de incertidumbre. Racimo a base de la teoria conductista resume estas tendencias ${ }^{84}$ a modo de resumen constan: la preferencia a un estadio medio que a un extremo, la inclinación hacia lo conocido y a mentener el status quo, el exceso de confianza y optimismo respecto a uno mismo, las estimaciones y valoraciones iniciales excesivas que motivan por ejemplo al pago de indemnizaciones ridículamente exuberantes, que tan dispuestos mentalmente se encuentran los juzgadores ${ }^{85}$, como se elije y jerarquiza la informacion con la cual se tomará una decisión, la preferencia a la omisión antes que al cometimiento de un delito aúnque causen el mismo efecto asi como de lo usual ante su opuesto y finalmente como los seres humanos buscan relacionar causas y consecuencias para decidir de la mejor forma posible pues el sentimiento de arrepentimiento podria afectar la conciencia de quien da una decisión final. La irracionalidad se ve limitada entonces por factores externos al juez ya que el mismo, al ser un humano, no está excento de ser víctima de estas tendencias.

Las normas juridicas reducen esta incertidumbre pues guian la conducta de los seres humanos, establece reglas por medio de las cuales quienes se someten a un determinado ordenamiento juridico adoptan decisiones racionales para no ser sujetos de sanciones, esto respecto a los ciudadanos. El problema respecto a este enfoque se encuentra en medir la racionalidad de los jueces frente a su elección en dos situaciones con pluralidad de acciones, para ello se requiere un metacriterio ${ }^{86}$ el cual se prestaría a la idea de preferencias subjetivas disfrazadas de criterios objetivos.

84 Racimo, 2004. 2.

85 Entiéndase por juzgadores al juez unipersonal de primera instancia y a los miembros de un jurado.

86 Metacriterio: Según Calvo Soler se trata de un criterio ordenador el cual desemboca en una mera cuestión de preferencias del agente. 
Los criterios al considerar pueden ser tecnicos como morales, es posible regir almenos los técnicos por medio del formalismo de manera que la autoridad y el procedimiento signifiquen una garantía para los ciudadanos de no caer en el libre albedrio del poder que crea, aún menos de quien aplica el Derecho. Pero ¿Qué criterios podrian ser cuasi objetivos y conjugarse con la subjetividad humana presente incluso en el juez? En primer lugar el juez en esencia debe poseer ciertas caracteristicas especiales como información suficiente, actitud imparcial y racionalidad ${ }^{87}$. No existe sistema judicial en el que el juez no deba sortear una serie de obstáculos (presiones) para mantener su imparcialidad al margen de la moralidad o inmoralidad de estos medios en el ejercicio profesional y particularmente en el litigio, tema sobre el cual se considera que existe mucho que decir, se puede dejar de lado el hecho que la independencia constituye uno de los principales requisitos de un magistrado ${ }^{88}$.

En segundo lugar existen criterios que buscan aportar objetividad a estas decisiones como: 1) Universidalidad respecto a las máximas de justicia que no es igual a la generalidad ${ }^{89}$ sino a que a todo actor que incide en el mismo comportaiento antijurídico le corresponda exactamente la mismo sanción. 2) Coherencia respecto a la compatibilidad y la consistencia lógica, este criterio se confirma con la sumisión de la norma a los principios y valores que plantea determinado sistema jurídico, por tanto no es puramente formal y es dinámica respecto al sujeto que argumenta. 3) Adecuación de las consecuencias para satisfacer un objetivo social valioso. 4) Moral social de la mayoria de la población aún cuando esta es difícil de conocer y no carezca de prejuicios. Y finalmente 6) Lo razonable del Derecho esta constituido por el cumplimiento de los requisitos formales que justifica una elección.

La reunión de estos criterios constituirá el equilibrio entre lo admisible respecto a los criterios objetivo-formales y subjetivo-morales, el punto medio entre las respuestas planteadas por las escuelas positivistas y naturalistas que más que probar una teoría busca la resolución de conflictos en favor de la justicia y no de la arbitrariedad judicial.

Resumir la manera en que se limita el poder judicial en el sistema anglosajón y continental presta varias explicaciones a la manera de

87 Atienza. (2011). Cómo evaluar las argumentaciones judiciales. 116.

88 Eguez Toledo, Haro Seijas y Zegarra Mulanich, 1995. 4.

89 Una norma especial también puede ser universalmente aplicada 
optar por una causa u otra, se presentan entonces la inducción y deducción respectuamente, debido a cuanto influencia la jurisprudencia que el caso del sistema anglosajón lleva por demás la delantera. Así mediante ella se establecen reglas institucionales del juzgamiento a la cual los actores le deben fidelidad e incluso delimitan el marco de la legitimidad, esto daría paso a pensar que aún bajo sus preferencias personales el juez; estas reglas proveen razones a sus decisiónes que va más alla de su subjetividad, crean sentido de deber y responsabilidad e incluso ponen en riesgo la reputación y retribución económica del mismo. Es la utilidad de los principios generales de esa sociedad antes que el abnegado deseo de justicia lo que estimula el fallo de los jueces y el destino de los procesados, esto explica el poderío de la función judicial en el sistema anglosajón.

No existe sistema judicial en el que el juez no deba sortear una serie de obstáculos (presiones) para mantener su imparcialidad Al margen de la moralidad o inmoralidad de estos medios en el ejercicio profesional y particularmente en el litigio, tema sobre el cual considera que existe mucho que decir, no se puede dejar de lado el hecho que la independencia constituye uno de los principales requisitos de un magistrado ${ }^{90}$. En el sistema continental la legitimidad y el control constitucional de carácter bastante positivista permiten la regulación simbiótica entre el Derecho y el poder, sea gracias al Estado de Derecho. Existen diversas maneras de regular esta relación de acuerdo con la fuente utilizada, de cualquier forma el gobernante se limita a lo que establecen la snormas juridicas y estos limites no deben ser reflejo del poder sino su restricción. Este ideal se ve violentado cuando el poder ejecutivo prácticamente legisla y los propios legisaladores en representación de los intereses comunes, esto doblega el poder judicial al ejecutivo. Para evitarlo, desde un punto de vista institucional es preciso rodear de un marco normativo a los magistrados de tal manera que se garantice su independencia ${ }^{91}$. La razón jurídica dogmática e indiferente, a gusto consigo misma, no tolera que se ponga en duda la feliz armonía que reina entre el Derecho y el Poder que tanto beneficia a los juristas y a los políticos ${ }^{22}$.

El excesivo número de abogados sin un caso los pone en la dura necesidad de escoger entre el honor profesional y la subsistencia. El

90 Horozco Enríquez, 2005. 4.

91 Abad, De Belaúnde, de la Jara y Pásara, 2003. 5.

92 León Vásquez y Castillo Córdova, 2008. 33. 
público, los clientes, mantienen un concepto duro y negativo de los jurisperitos ya que su función se ha envuelto en el lucro y la malicia. La función del abogado debe exponerse sin los aspectos negativos que hoy la envuelven.

Jonathan Swift en sus Viajes de Gulliver expresó mediante el rey que: "era una lástima que criaturas dotadas de tan prodigiosas habilidades mentales como deberían ser ciertamente aquellos abogados cuya descripción yo hacía, no se sintieran inclinadas a ser instructores de otros en sabiduría y conocimiento". Ciertamente es una pena que del abogado no emerjan soluciones benévolas y satisfactorias para el cliente. La venganza y la necesidad de ver al oponente devastado han creado seres repudiables y altisonantes.

Al Abogado le corresponde el arte de simplificar para sus oyentes las complejas normas y caminos jurídicos, para ello debe ser más práctico y hacer que estos escuchas no solo lo admiren por su facilidad de palabra sino confíen en él y se sientan bien representados para que en los casos más adversos sepan que deben cumplir con lo que su defensor consiguió no solo por coacción estatal, sino porque a esa solución la ampara la justicia y la nobleza de ser el mejor remedio a determinado mal. Eso es lo que representan los abogados: seres al servicio de otros seres, que facilitan el paso a la justicia con sus habilidades de defensa y clara explicación.

El abogado es necesario en la sociedad y su presencia es más indispensable en la medida en que la sociedad es cada vez más compleja, en que las relaciones entre los hombres son más numerosas e intensas ${ }^{93}$.

\section{DESDE LA ENSEÑANZA DEL DERECHO}

El propósito original del Derecho, acorde a la historia romana, no fue lucrar. En Roma quienes asesoraban a quienes tenían problemas dentro de la cives lo hacían por honor, mantener el orden, intenciones benévolas y no por un monto económico, un ejemplo de ello es Cicerón. Buscar respuestas y resultados, la administración humana de justicia, el bien general; En estas pocas palabras se puede centrar el propósito del Derecho. Existe una intención más

93 Chudson, Mejía y Del Mastro Puccio, 2014. 
allá de la acumulación de capital para cada operador del Derecho, existe un ideal de hacer justicia.

Para cumplir los antes mencionados objetivos es necesario mostrar como el Derecho se acopla a la realidad, cambia e intenta ir más allá de una sociedad llena de normas ultracoactivas, sino más bien mitigar y reformar los aspectos y comportamientos negativos en la sociedad. Cuando los individuos confíen en la neutralidad de su sistema legal llegarán a acuerdos y conciliaciones asistidas, en lugar de peleas desgastantes que no encuentran soluciones, por el contrario, hallan más conceptos huecos y preguntas sin responder.

El Derecho se maneja con un metalenguaje (lenguaje de conceptos), los mismos que son autopoiéticos, es decir que se generan en sí mismo. Los conceptos jurídicos son complejos y en ocasiones sin ninguna aplicación práctica que no sea lucirse ante quienes se denominarían "ignorantes del Derecho". Cabe entonces preguntarse: ¿cuál es el verdadero uso y función de estos conceptos? A lo que después de una lectura medianamente ligera se puede responder con que estas concepciones son instrumentos de la fase teórico-formativa o el primer paso que avanzará hacia el raciocinio, para finalizar con su aplicación en el mundo real. El lenguaje usado por el Derecho es un mundo aparte donde solo quienes pueden manejar estos conceptos viven.

Quienes crean teoría jurídica, en su mayoría, repiten literalmente lo que sus antecesores, pero con nombres distintos y pomposos, como por ejemplo las divisiones pedagógicas en Derecho público y privado que varían de autor a autor, aunque se refieren a lo mismo, esto degenera en una mafia donde solo aquellos cultos del metalenguaje jurídico conocen y debaten de Derecho, cuando fue creado para regir a la sociedad, es más se presume de su conocimiento. Mucha de la doctrina debe ser leída con conciencia que varias veces se repite el mismo tema con títulos diversos.

Así mismo, el positivismo y los mismos operarios del Derecho intentan facilitar su trabajo al pretender hacer de él una ciencia estática, lo cual resulta impensable. La globalización, los cambios económicos, los avances científicos y tecnológicos exigen que la normativa y su ejecución se adecuen a la realidad. Por ello estos conceptos, actualmente mal utilizados, deben tener un carácter dinámico y útil. 
Para esbozar soluciones práctico-teóricas a las falencias educativas, encaminar la educación legal hacia el éxito de los futuros abogados del Ecuador y a la real y justa aplicación de la normativa jurídica se debe analizar el proceso de enseñanza del Derecho, así como el de toda ciencia, posee falencias que deben se deben establecer y solucionar. La permuta de conocimiento requiere estudio y entrega de dos actores: Profesor y alumno. Ambos con sus funciones específicas, deben servir al otro como fuente de suma y no sustracción. Actualmente la enseñanza del Derecho ha avanzado muchísimo, pero posee partes oscuras y problemáticas.

"Mirando el plan de estudios de una escuela de Derecho y escogiendo cualquier curso considerado muy importante, me hago esta pregunta: ¿Podría haberme convertido en un abogado y juez de éxito si no hubiera tenido este curso? La respuesta es sí. Sin embargo, ¿̇puedes triunfar sin un fondo y una base que te de bienestar, inteligencia emocional, salud mental y física, relaciones sanas, entre otros? Si no tienes esa base, también vas a fracasar profesionalmente." ${ }^{{ }_{4}}$

Establecer los desperfectos de la educación inicial del Derecho es importante porque no es posible que desde el comienzo se trabaje con conceptos huecos que complican la completa asimilación de la materia o incluso algunos conceptos útiles, de los cuales su función y aplicación real no fue especificada por el profesor. Aprender un concepto debe representar un logro real para el alumno.

El torero se conforma en el ruedo, así mismo el abogado en la práctica. Las facultades de Jurisprudencia deben ofrecer a sus alumnos armas teóricas como prácticas. No es posible hablar de una educación integral si esta no sirve al salir de sus aulas.

El Estudiante aprende a pelear antes que, a utilizar métodos alternativos de solución, como la mediación, que generen confianza en lugar de temor; tampoco se le enseña a razonar y generar soluciones sino a memorizar para escribir ensayos, pruebas y más ensayos sin valor. La enseñanza del Derecho debe acoplarse a la realidad para su ejecución en la práctica.

En Estados Unidos, existe un cuento tradicional que dice lo siguiente: si me das un libro contándome de pescar, lo leeré y quizá me guste,

94 Chudson, Mejía y Del Mastro Puccio, 2014. 
pero si eso es todo lo que tengo, tendré hambre por el resto de mi vida. Llévame a pescar y enséñame cómo hacerlo y quizá pueda sobrevivir por el resto de mi vida. Pero si me das un libro, me llevas a pescar y me dejas aprender a cómo hacerlo, mi barriga estará llena por siempre ${ }^{95}$.

El profesor que provea conocimiento, sin acaparar la posibilidad de expresar sus ideas, y enseñe a generarlo suplirá las necesidades y ambiciones de sus alumnos. Además, el otro extremo consistente en dejar hablar a todos y no poder llegar a una conclusión, resultaría perjudicial. Llegar a un punto medio entre una clase magistral y participativa sería la opción ideal de retroalimentación para la clase.

A los profesores no se les ha "enseñado a enseñar" por ello tienen que innovar, mediante un proceso de intento, fallo y rectificación cada profesor encontrará el método más provechoso para lograr su tarea: formar cerrando de a poco la brecha entre adquirir conocimiento inútil y preparar a los futuros abogados (hábiles y prácticos) de su nación. Cada profesor debe desarrollar un método específico que funcione con determinada clase.

"Aprender a aprender" es esencial para el alumno y el profesor, esa habilidad no se logra en clases magistrales de cursos teóricos, sino en talleres, en el desarrollo del razonamiento e investigación. La Interdisciplinariedad de las ciencias y su ejercicio de la profesión ampliarán los horizontes del abogado o del estudiante de Derecho a tal punto que podrá detectar soluciones que favorezcan a su cliente en todos los sentidos y harán que su mente vaya más allá de lo que se ha impartido en clase.

De la educación de cada abogado del país depende el funcionamiento del sistema legislativo y judicial, en sus manos estará la aplicación de justicia y el referente jurídico de humanidad de la nación ¿̇no es entonces gravitante que sean personas capaces quienes asuman estas tareas? Establecer las falencias e incongruencias desde la enseñanza del Derecho, dentro de cada facultad de jurisprudencia, es trascendental. Es allí donde se debe erradicar el nacimiento toda forma débil, ilógica e incoherente de normativa jurídica. El objetivo del Derecho desde siempre ha sido normar la sociedad para evolucionar conjuntamente, para lograrlo es necesario proponer opciones realistas, mismas que al ser ejecutadas encaminen a estos centros de aprendizaje a la forma-

95 Chudson, Mejía y Del Mastro Puccio, 2014. 
ción de profesionales hábiles, útiles a la colectividad y con conciencia de la realidad nacional.

El Derecho a lo largo del espacio y tiempo ha buscado la verdad, por medio de soluciones a conflictos que se generan en el entramado de las relaciones sociales. Para conseguir estos fines es necesario buscar un camino óptimo, a lo que llamaremos método. La doctrina positivista y sus adeptos buscan una aplicación rígida del Derecho en la cual se usa la idea de Montesquieu que el juez solo debe realizar una aplicación exegética del Derecho. Asimismo, limitarse al uso del método deductivo resulta necio frente al carácter dinámico de la sociedad. Nace entonces una pregunta ¿Cómo dinamizar el Derecho desde su metodología? Indicar nuevos métodos de razonamiento es el paso inicial que encamina la normativa jurídica hacia la realidad, gracias a la adopción e integración de otras ciencias será posible llegar a la verdadera ciencia social. Los conflictos de intereses han Estado presentes en la historia a la par que el humano. Al ser la violencia un medio nada óptimo para resolverlos la figura de un tercero que juzga se implementó. Hoy en día el poder judicial es parte de muchos sistemas jurídicos en pro de la armonía social pero que es lo que motiva a los jueces a inclinarse hacia una causa u otra ¿es acaso la lógica, la razón o la simple preferencia subjetiva? Esto genera algunos problemas por lo cual es necesario exponer aquellos que se presentan a lo largo de la actividad judicial según el sistema anglosajón y continental, que condiciona a nivel psicológico la racionalidad del juez y que limite hace frente a este poder de decisión tan grande. Solo al comprender el contexto de argumentación por completo es posible comprender las decisiones judiciales.y como los sentimientos y la racionalidad de conjugan.

\section{CONCLUSIONES}

La argumentación, la expedición de normas e incluso más la aplicación de la normativa jurídica dependen de la correcta asimilación lógica y analítica del operario, por lo que es impensable separar al Derecho y la coherencia-lógica. Es importante considerar que la argumentación jurídica es el proceso escrito y oral que los juristas utilizan para persuadir a sus interlocutores respecto a sus interpretaciones de la norma jurídica, aún así, su estructura debe ser susceptible a verificación. Para que exista el argumento persuasivo debe existir una estructura lógica del argumento que pueda ser susceptible de no caer en 
contradicción. Esto demanda un examen del lenguaje desde la lógica formal o material.

La enseñanza del Derecho debe contemplar tres aspectos: buenas bases teóricas, desarrollo de habilidades y experiencia adquirida mediante una mezcla teórica y práctica, ambas no pueden prescindir de la argumentación lógica que debe ser impartida desde las nociones más esenciales del pregrado pues sustentarán su pensar y actuar. El estudiante de Derecho además debe contar con el poder de persuasión propio de la argumentación jurídica que enlaza la normativa, los conceptos y la habilidad del operador jurídico.

El abogado debe poseer un catálogo variado de destrezas jurídicas como: la lectura, la redacción, la expresión verbal, no verbal, el empleo hábil de la sustentación lógica y la investigación. El abogado debe también desarrollar habilidades interpersonales, como son la capacidad de trabajo en equipo, las buenas relaciones con las personas del entorno y el buen trato al cliente.

Para la dinamización del Derecho es primordial evitar la absolutización de un solo método, La función del juez va a más allá de una simple aplicación mecánica y al ser así sus fallos deben estar motivados de manera interna y externa. El método deductivo ayuda al control de la lógica interna que deben tener las sentencias en favor de validez, pero se puede prescindir de otros pues la actividad judicial tiene varias fases y en cada una tiene un proceso intelectual es diferente.

Las nuevas propuestas, las mismas que recogen la maxificación de beneficios, mediante el proceso ensayo-error de la Economía austriaca y el uso conjugado de métodos encaminan al Derecho a ser una verdadera ciencia social tan dinámica como su materia de estudio: la sociedad. Estas propuestas muestran la utilidad y eficiencia de las normas y la actividad judicial de modo que representen el nivel intelectual y humanístico con el que cada Estado se maneja social y jurídicamente. 


\section{REFERENCIAS BIBLIOGRÁFICAS}

Abad, S., De Belaúnde, J., de la Jara, E. y Pásara, L. (2003). Reforma del poder Judicial. Revista Jurídica Themis 47.

Atienza, M. (2005). Las Razones del Derecho: Teorías de la argumentación jurídica. Revista Jurídica de la UNAM.

Atienza, M. (2011). Cómo evaluar las argumentaciones judiciales. Revista jurídica de la UNAM, 113-134.

Baca d'la Zota, W. (1989). Poder Judicial y realidad. Revista jurídica Themis 47.

Blume, R. (1990). Los abogados y el teatro. Revista jurídica Themis, 2.

Brion, D. J. (2009). Normas y valores del análisis económico del Derecho. Revista jurídica Themis.

Chudson, C. B., Mejía, T. y Del Mastro Puccio, F. (2014). Revista jurídica Themis, 4 .

Eguez Toledo, J. A., Haro Seijas, J. J. y Zegarra Mulanich, G. (1995). El poder judicial: La visión de los magistrados. Revista jurídica Themis 249.

Figueroa Navarro, A. M. y Huayta Rodríguez, M. E. (2014). Deducción y deductivismo: reflexiones sobre su funcionalidad en la decisión judicial. Obtenido de http://perso.unifr.ch/Derechopenal/assets/files/ articulos/a_20110107_03.pdf

Fraga Lo Curto, L. (s.f.). Eficiencia dinámica y análisis praxeológico del Derecho. Universyté Lyon III.

Horozco Enríquez, J. (2005). Justicia constitucional electoral y garantismo jurídico. Revista Jurídica UNAM.

Huerta Ochoa, C. (2015). Interpretación y argumentación en el Derecho. Revista Jurídica de la UNAM.

León Vasquez, J. y Castillo Córdova, L. (2008). Poder judicial versus Poder Ejecutivo. Revista Jurídica Themis 55. 
Lionetti de Zorzi, J. P. (s.f.). Razonamiento Jurídico y toma de decisión. Breves notas acerca de la influencia de la racionalidad y la irracionalidad en la decisión judicial. Revista Universitas, 3-22.

Magaloni Kerpel, A. L. (2016). ¿Cómo estudiar el Derecho desde una perspectiva dinámica?. Revista jurídica de la UNAM.

Méndez Reátegui, R. C. (2008). El Análisis Económico del Derecho: Principales escuelas que han influenciado en el Perú, aportes y su contraposición conceptual. Perú: Universidad Nacional Mayor de San Carlos.

Posner, R. (2002). Análisis Económico del Derecho. Revista Jurídica ICESI.

Racimo, F. (2004). El análisis conductista del Derecho. Revista de Doctrina y Jurisprudencia PUCA, 2.

Serrano Migallón, F. (2015). Guia de Estudio sobre el Análisis Económico del Derecho. Revista Jurídica de la UNAM.

Suárez Romero, M.Á. y Conde Gaxiola, N. (2009). Argumentación jurídica. Revista jurídica de la UNAM.

Recibido: 02/08/2017

Aceptado: $24 / 11 / 2017$

María Isabel Zamora Zumárraga: Investigadora Jurídica del estudio Cevallos \& Noboa.

Correo electrónico: isabel_zamora@hotmail.com 